\title{
Diagnostic strategies and the incidence of prostate cancer: reasons for the low reported incidence of prostate cancer in China
}

\author{
Ling Zhang ${ }^{1}$, Shan $\mathrm{Wu}^{2}$, Li-Rong Guo ${ }^{1}$, Xue-Jian Zhao ${ }^{1}$ \\ ${ }^{1}$ Department of Pathophysiology, Prostate Diseases Prevention and Treatment Research Centre, ${ }^{2}$ Department of Patho- \\ logy, Norman Bethune Medical School, Jilin University, Changchun 130021, China
}

\begin{abstract}
We have analysed the reasons for the low reported incidence of prostate cancer in China and argue for early diagnosis and treatment of this disease. According to the 2002 database of the International Agency for Research on Cancer (IARC), the age-standardized incidence of prostate cancer in China is $1.6 / 10^{5}$ person years (PY), with a mortality rate of $1.0 / 10^{5}$ $\mathrm{PY}$ and mortality-to-incidence rate ratio $(\mathrm{MR} / \mathrm{IR})=0.63$. The MR/IR ratio of prostate cancer in China was found to be higher than the average in Asia $(\mathrm{MR} / \mathrm{IR}=0.57)$ and much higher than that in North America $(\mathrm{MR} / \mathrm{IR}=0.13)$. These data indicate that in China most prostate cancers were in the advanced stages at the time of diagnosis, and that patients had a short survival time thereafter. In 2004, Stamey et al. reported a retrospective American study of prostate cancer for the years 1983-2003. It was shown that most cases of prostate cancer detected by prostate-specific antigen (PSA) screening were in the advanced stage at the start of this 20 -year period. These early follow-up data are quite similar to the results obtained from mass PSA screening of elderly men in Changchun, China. However, after the American programmes for early diagnosis and treatment of prostate cancer were accepted, tumours were diagnosed at earlier stages. On the basis of these findings, mass screening should be performed in the whole of China using serum PSA to facilitate early diagnosis and treatment of prostate cancer.
\end{abstract}

Asian Journal of Andrology (2009) 11: 9-13. doi: 10.1038/aja.2008.21; published online 1 December 2008.

Keywords: diagnosis, metastasis, prostate cancer, prostate carcinoma tumour antigen

\section{Introduction}

Cancer is one of the most lethal diseases and has been actively studied for many years. If cancer could be detected and treated at an early stage, the duration and quality of life could be improved for many people.

A report [1] on cancer in Caucasian Americans showed that the highest 5-year survival rate was for prostate cancer $(99 \%)$, followed by thyroid cancer $(97 \%)$. Improved survival rates for cancer patients have been associated

Correspondence to: Prof. Xue-Jian Zhao, Department of Pathophysiology, Prostate Diseases Prevention and Treatment Research Centre, Norman Bethune Medical School, Jilin University, Xinmin Street, Changchun 130021, China.

Fax: +86-431-8563-2348 E-mail: pro_2@jlu.edu.cn

Received: 28 September 2008 Accepted: 3 October 2008

Published online: 1 December 2008 with scientific progress and especially with diagnostic screening [2].

According to the International Agency for Research on Cancer (IARC), the incidence of prostate cancer in China was $1.1 / 10^{5}$ person years (PY) in 1990 [3] and $1.6 / 10^{5} \mathrm{PY}$ in 2002 [4]. China is considered to have the lowest incidence of prostate cancer in the world. A comparative study [5] showed that the incidence in Chinese men who had lived for long periods of time in the mainland United States was much higher than that in Chinese men included in the IARC data. The fundamental difference between ChineseAmericans and Chinese men was that Chinese-Americans had received serum prostate-specific antigen (PSA) mass screening and early treatment for prostate cancer.

In this review, we analysed the reason for the low reported incidence of prostate cancer in China by comparing patterns of prostate cancer incidence, mortality and 
prevalence across five continents. We have also analysed representative publications from the United States regarding mass screening with serum PSA, and have reviewed population data on prostate cancer in Changchun City. Our goal is to promote the early diagnosis and treatment of prostate cancer in China.

\section{Comparisons of worldwide cancer incidence, mor- tality and prevalence in five continents}

Prostate cancer is a common disease in elderly men. In 2006, Kamangar et al. [6] provided an overview of worldwide cancer incidence, mortality and prevalence during 1993-2001. This analysis included an extensive discussion of the eight most common cancers in five continents. Lung cancer was uniformly the most common, and prostate cancer was in fifth place. During the years 1973-1977, prostate cancer incidence rates increased in all parts of the world, but were nearly sixfold higher in more developed regions as compared with less developed regions [6]. Worldwide, for the years 1993-2001, 679060 patients were reported to suffer from prostate cancer every year, and the incidence rate of prostate cancer is $25.3 / 10^{5}$ PY. Every year, 221036 patients were reported to die from prostate cancer with a mortality rate of $8.2 / 10^{5} \mathrm{PY}$ (mortality-to-incidence rate ratio $[\mathrm{MR} / \mathrm{IR}]=0.32$ ). The incidence of prostate cancer in different continents has also been compared. In North America, the number of cases of prostate cancer reported annually was 257943 , and the incidence was $119.9 / 10^{5} \mathrm{PY}$. Additionally, 36447 patients died, and the mortality was $15.8 / 10^{5} \mathrm{PY}(\mathrm{MR} /$ IR = 0.13). Meanwhile, in Asia, 70317 patients were diagnosed with prostate cancer every year. The incidence was $4.7 / 10^{5} \mathrm{PY}, 40126$ patients died, and the mortality was $2.7 / 10^{5} \mathrm{PY}(\mathrm{MR} / \mathrm{IR}=0.57)$ (all data were taken from Kamangar et al. [6]).

Some research data [7] have shown that the survival rate for patients with early-stage prostate cancer (located beneath the prostate capsule) is as high as $100 \%$, whereas the 5 -year survival rate is only $49 \%$ for patients with prostate cancer metastases. At the time these data were reported, programmes for early diagnosis and treatment of prostate cancer were already commenced in North America [8]. Although (as noted above) the incidence was as high as $119.9 / 10^{5} \mathrm{PY}$, the MR/IR ratio was only 0.13 . However in Asia, this ratio was as high as 0.57 . Thus, in Asia, more than half of the prostate cancer patients died in the same year that they were diagnosed. These data suggest that most prostate cancer patients in Asia had advanced local disease or metastases by the time they were diagnosed.

\section{Prostate cancer incidence and mortality in China}

According to the 2002 IARC [4] database, the age- standardized incidence of prostate cancer in China was $1.6 / 10^{5} \mathrm{PY}$, with a mortality rate of $1.0 / 10^{5} \mathrm{PY}$ and MR/IR $=0.63$. These statistics are based on comprehensive data obtained from all tumour registry centres in China. For a relatively long time, the incidence of prostate cancer in China was considered to be the lowest in the world, although the mortality rate was higher than average in Asia (MR/IR = 0.57 in Asia [6]) and much higher than in North America. In the developed areas of China, such as Shanghai and Beijing, the incidence of prostate cancer was higher than that reported by IARC, although this incidence rate was also generated from clinical epidemiology statistics. For example, in Shanghai City, the incidence of prostate cancer was $1.6 / 10^{5} \mathrm{PY}$ in 1973 and $7.7 / 10^{5} \mathrm{PY}$ in 2000 [9]. Thus, the incidence increased by almost 4.8 -fold in 27 years, and prostate cancer became the most common cancer in males in this geographic area. Other data from the Urological Institute of Peking University describing the incidence of genitourinary cancer over the past 50 years have shown that the incidence of prostate cancer among hospital in-patients increased dramatically from 3.3\% to $13.4 \%$ during the 1980 s [10]. Retrospective surveys of eight hospitals in Changchun City also show that the annual average incidence of prostate cancer during the 3 years between 1999 and 2001 was 4.72-fold greater than that during the years from 1986 to 1989. A more extensive analysis of 358 cases of prostate cancer revealed that $72.4 \%$ of the patients were already in clinical stages C and D. Only 4 of those 358 men received radical prostatectomy [11]. We infer that, in China, most prostate cancers are diagnosed on the basis of finding a mass by digital rectal examination or by diagnostic imaging, and that few cases are detected by elevated levels of PSA in the serum.

\section{Data from a Changchun City mass screening pro- gramme for prostate cancer using PSA}

In 1999, a mass screening programme for prostate cancer using PSA was initiated in Changchun City for men over the age of 50 years. This programme was supported by the China-Japan Intergovernmental Special Technical Cooperation Projects. After the first 4218 men had been screened, the age-adjusted (over 50 years old) cancer detection rate was $0.78 \%$. After adjustment for the secondary examination rate, the cancer detection rate reached $1.28 \%$ [12], which is higher than the rate detected in Natori, Japan [13]. After screening 12027 men, the cancer detection rate (after adjustment for secondary examination rate) reached $1.71 \%$. Men with clinical stage $\mathrm{C}$ and D disease accounted for $42.1 \%$ of cancer patients. More than $20 \%$ of the patients had lymph node and bone metastases [14]. These mass screening results indicate that Chinese men suffer from different types and stages of prostate cancer. The low incidence of prostate cancer 
in China might therefore be a consequence of different diagnostic strategies.

In 2007, McCracken et al. [5] performed a comparative study on the incidence and mortality of seven types of cancer in 2000-2002, in persons who had lived for a long period of time in the mainland United States. The study population included Chinese, Filipino, Vietnamese, Korean, Japanese, Asian/Pacific Islander and non-Hispanic Caucasian persons. The incidence of prostate cancer for Chinese-Americans was $80.4 / 10^{5} \mathrm{PY}$, with a mortality rate of $8.9 / 10^{5} \mathrm{PY}$ and $\mathrm{MR} / \mathrm{IR}=0.11$. The incidence of prostate cancer for Chinese-Americans was just $1 / 2$ that of Caucasians in the United States. The mortality rate was also lower than that of Caucasians $(\mathrm{MR} / \mathrm{IR}=0.17)$. When we compared the data for Chinese men from the IARC report of 2004 with that of the California Cancer Registry, we found that the incidence of prostate cancer was 50.3-fold higher for Chinese-Americans than for men in China. Additionally, the mortality rate for men in China was 8.9-fold higher than for Chinese men in America. The MR/IR ratio was 0.11 for Chinese-Americans, but it was 0.63 for Chinese men (Table 1). Both Chinese-American and Chinese men in China have a similar genetic background, raising the question of why such a large difference exists between these populations in the incidence and mortality of prostate cancer. We believe the defining factor to be the participation of Chinese-Americans since 1989 in mass screening for prostate cancer by serum PSA measurement. In the United States, annual serum PSA analysis has become a routine behaviour. In contrast, mass screening for prostate cancer in China has not been performed, mainly because of misleading clinical epidemiology data. The difference in incidence and mortality between Chinese-American and Chinese men is therefore likely caused by the different diagnostic strategies used in China and the United States.

The implementation of prostate cancer screening in the United States should therefore be used as a template for diagnosis and treatment in China to decrease the mortality of this disease.

\section{Prostate cancer was diagnosed at late stages in the United States 20 years ago}

In 1983, the advocacy of Stamey et al. [15] led to the establishment of the first mass screening programme for prostate cancer using serum PSA detection. Subsequently, during the period from 1987 to 1989 , similar programmes for early diagnosis and treatment of prostate cancer were quickly popularized all over the United States [16]. The overview of cancer in five continents by Kamangar et al. [6] covered the years from 1993 to 2001. By 1993, mass screening for prostate cancer with serum PSA had already been conducted for 10 years in the United States. Thus, from 1993 to 2001, the reported incidence of prostate cancer in the United States was higher than that of lung cancer and became the most common cancer in men. Its mortality was ranked second $[17,18]$.

Stamey et al. [19] performed a retrospective study on 1317 prostate cancer patients who were diagnosed through the 1983-2003 PSA mass screening programme and whose tumours were confirmed by radical prostatectomy. These 20 years were divided into four intervals. The results showed the following: (1) The average PSA level at diagnosis decreased during these 20 years. In the first 5 -year period, the average serum PSA level was $24.74 \pm$ $38.00 \mathrm{ng} \mathrm{mL}^{-1}$, whereas it was $20.01 \pm 21.61 \mathrm{ng} \mathrm{mL}^{-1}$ in the second 5-year period. In the third 5-year period, serum PSA decreased to $10.22 \pm 9.05 \mathrm{ng} \mathrm{mL}^{-1}$ and was even lower $(8.14$ $\pm 9.70 \mathrm{ng} \mathrm{mL}{ }^{-1}$ ) in the fourth 5 -year period. This illustrates that the mass screening of serum PSA could gradually decrease the stage of prostate cancer at diagnosis. (2) The frequency of palpable nodules on digital rectal examination was $90.79 \%$ in the first 5 -year period, but for the following three 5-year intervals this number was $58.02 \%, 38.54 \%$ and $16.76 \%$, respectively. This shows that mass screening of serum PSA could find early-stage prostate cancers that could not be detected using traditional techniques. For example, in the fourth 5 -year period, $83.2 \%$ of prostate cancer patients would have remained undiagnosed if the diagnosis was dependent on digital rectal examination and imaging techniques alone. (3) Radical prostatectomy specimens were examined sequentially in $3-\mu \mathrm{m}$ sections by one pathologist. The results were as follows: (1) The mean volume of the largest cancer decreased significantly from $5.33 \pm 6.59 \mathrm{~cm}^{3}$ in the first 5-year period to $4.93 \pm 5.59,3.76$ \pm 4.37 and $2.44 \pm 3.04 \mathrm{~cm}^{3}$ in the following three 5-year periods, respectively. (2) Seminal vesicle invasion was found in $23.03 \%$ of specimens in the first 5 -year period; this fraction then decreased to $6.96 \%, 4.74 \%$ and $5.41 \%$, respectively. (3) The depth of prostate capsule invasion was $1.54 \pm 2.78 \mathrm{~cm}$ in the first 5-year period and then decreased to $1.02 \pm 2.32,0.57 \pm 2.22$ and $0.22 \pm 0.80 \mathrm{~cm}$, respectively. (4) Peripheral lymph node metastasis was detected in $12.5 \%$ of specimens in the first 5-year block; this fraction then decreased to $7.17 \%$ and $4.55 \%$ in the following two 5 -year periods and was entirely absent in the last 5-year period (data

Table 1. Age-adjusted incidence and mortality of prostate cancer (per 100 000).

\begin{tabular}{lccc}
\hline & Incidence & Mortality & MR/IR \\
\hline Chinese men $^{\mathrm{a}}$ & 1.6 & 1.0 & 0.63 \\
Chinese-Americans $^{\mathrm{b}}$ & 80.4 & 8.9 & 0.11 \\
Non-Hispanic White men $^{\mathrm{b}}$ & 159.9 & 27.0 & 0.17 \\
\hline
\end{tabular}

${ }^{\mathrm{a}}$ From Lyon: IARC Press; $2004 ;{ }^{\mathrm{b}}$ From the California Cancer Registry (2000-2002), CA Cancer J Clin 2007; 57: 190-205. Abbreviation: MR/IR, mortality-to-incidence rate ratio. 
were extracted from Table 3 in reference [19]).

This retrospective study showed that in the 20 years from 1983 to 1988 , most parameters, including serum PSA, palpable nodules on digital rectal examination and pathological features, indicated prostate cancer in an advanced stage. These data are quite similar to the results of PSA mass screening of 12027 men over the age of 50 years in Changchun, where $42.1 \%$ of patients had clinical stage $\mathrm{C}$ or D disease and $20 \%$ of patients had bone marrow or lymph node metastasis at the time of diagnosis [14].

Ji et al. [20] have analysed 88 adenocarcinoma cases from the mass screening programme in Changchun. These 88 cases had a final diagnosis of prostate adenocarcinoma by prostate biopsy and were divided into two groups. One group included 58 patients with hypoechoic images (hypoechoic group) on ultrasound examination. The second group included 35 patients without any abnormal morphology on ultrasound (normal group). None of the clinical stage A prostate cancers were detected by ultrasound ( $0 / 24$ cases). The missed diagnosis rate was $29.42 \%$ (5/17 cases) for prostate cancer in stage B and $24.0 \%$ in stage $C(6 / 25$ cases $)$. Only prostate cancers in clinical stage D were detected $100 \%$ of the time by ultrasound. These results provide further evidence that traditional diagnostic strategies for prostate cancer do not reflect the real status of prostate cancer in China.

Gao et al. [21] extensively analysed the pathological characteristics of prostate cancers detected by mass screening in Changchun. The results showed that $25.9 \%$ of elderly men with serum PSA $>4.0 \mathrm{ng} \mathrm{mL}^{-1}$ were found to have prostate cancer by ultrasound-guided transrectal six-sextant biopsies. Cases with Gleason scores $\geq 7$ accounted for $56.2 \%$ of patients, whereas cases with Gleason scores of 8 and 9 accounted for $17.1 \%$. These results correspond to the finding that $20 \%$ of prostate cancer patients in the same mass screening programme had bone and/or lymph node metastases at the time of diagnosis (that is, high grade, late-stage disease). Using the database and sample library of the mass screening in Changchun, Mao et al. [22] detected PSA mRNA and its protein expression by mononuclear cells in the peripheral blood of patients. This method can indirectly reflect prostate cancer with micro-metastases [23]. This study showed that although some patients were asymptomatic and did not see their physician, the presence of PSA mRNA and protein indicated micro-metastasis.

\section{No current test can replace serum PSA for mass screening of prostate cancer}

One purpose of the retrospective study by Stamey et al. [19] was to look for a new protein marker for prostate cancer. According to this study, serum PSA at diagnosis had decreased to $8.14 \pm 9.04 \mathrm{ng} \mathrm{mL}^{-1}$, a level where there is no correlation with pathologic parameters. Serum PSA levels were only correlated with tumour volume, making it difficult to separate early-stage prostate cancer from benign prostate hyperplasia. However, to date, no new markers have been found for replacement of PSA in mass screening programmes. For example, Pan et al. [24] examined serum samples from 83 prostate cancer patients and 95 healthy men in Changchun, China. Molecular protein profiling was carried out using surfaceenhanced laser desorption/ionization time-of-flight mass spectrometry. The spectral data were analysed using two bioinformatics tools. Eighteen differentially expressed proteins were identified in the sera of the cancer group as compared with the control group $(P<0.01)$; four proteins were upregulated and 14 downregulated. A decision tree classification algorithm that used an eight-protein mass pattern was developed to correctly classify the samples. A sensitivity of $92.0 \%$ and a specificity of $96.7 \%$ for the study group were obtained by comparing the carcinoma and control groups. However, there are many limitations to the mass screening of prostate cancer in China using this technique, including the high cost of equipment and protein chips.

Recent years have seen technical and analytical improvements to the use of serum PSA for prostate cancer diagnosis. For example, Li et al. [25] found that prostate cancer reduces the serum zinc concentration. The measurement of zinc levels in mass screening samples from Changchun improved prostate cancer detection in the 'grey zone' when compared with the free/total PSA (f/t PSA) ratio and total PSA. Zhang et al. [26] found that the PSA (f/t PSA) ratio could increase the rate of diagnosis for prostate cancer and was better correlated with histological diagnosis. $\mathrm{f} / \mathrm{t}$ PSA $<0.15$ provided an improved rate of prostate cancer detection when the PSA content was in the range of $4.0-10 \mathrm{ng} \mathrm{mL}^{-1}$. In this situation, the sensitivity of screening was $57.1 \%$ and the specificity was $63.8 \%$. The diagnostic rate reached $22.9 \%$ when coupled with biopsy by ultrasonic guidance, given f/t PSA ratios under 0.10 and PSA content in the range of 2.5-4.0 $\mathrm{ng} \mathrm{mL}^{-1}$ [27, 28]. In addition, PSA density and PSA volocity were other important potential references for prostate cancer diagnosis [29, 30]. At present, diagnostic strategies to detect prostate cancer in China still mainly rely on digital rectal examination and imaging. In our opinion, these approaches are unlikely to help detect cancer in many elderly men. Widespread mass PSA screening all over China is most likely to be necessary for achieving early diagnosis and treatment of prostate cancer.

\section{Summary}

According to the 2002 database from the IARC, the age-standardized incidence of prostate cancer in China 
was $1.6 / 10^{5} \mathrm{PY}$, with a mortality rate of $1.0 / 10^{5} \mathrm{PY}$ and $\mathrm{MR} / \mathrm{IR}=0.63$. The mortality rate of prostate cancer in China was higher than the average in Asia (MR/IR = 0.57 in Asia) and much higher than that in North America $(\mathrm{MR} / \mathrm{IR}=0.13$ in North America), indicating that most prostate cancers were in an advanced stage by the time of diagnosis. The patients had lost the opportunity to be treated with radical prostatectomy and had a short survival time after diagnosis.

The current state of prostate cancer diagnosis in China is similar to the one that existed in the United States during the period from 1983 to 1988, before the wide acceptance of population PSA screening. Mass PSA screening should be performed annually for Chinese men over the age of 50 years to achieve early diagnosis and treatment.

\section{Acknowledgment}

This study was kindly supported by a research fund from the Japan International Cooperation Agency (JICA) and the Ministry of Science and Technology of China. We thank Professor Frederick William Orr for his critical reading and revising of our manuscript.

\section{References}

1 Ries LA, Melbert D, Krapcho M, Stinchcomb DG, Howlader N, et al. SEER Cancer Statistics Review, 1975-2005, National Cancer Institute. Bethesda MD. http://seer.cancer.gov/csr/1975 2005/, based on November 2007 SEER data submission, posted to the SEER web site, 2008.

2 Collin SM, Martin RM, Metcalfe C, Gunnell D, Albertsen PC, et al. Prostate-cancer mortality in the USA and UK in 1975-2004: an ecological study. Lancet Oncol 2008; 9: 445-52.

3 Ferlay J, Bocani GLO. Cancer Incidence and Mortality Worldwide. Lyon: IARC Press; 1998.

4 Ferlay J, Bray F, Pisani P, Parkin DM. Globocan 2002: cancer incidence, mortality and prevalence worldwide. IARC Cancer-Base No 5, version 2.0. Lyon: IARC Press; 2004.

5 McCracken M, Olsen M, Chen MS Jr, Jemal A, Thun M, et al. Cancer incidence, mortality, and associated risk factors among Asian Americans of Chinese, Filipino, Vietnamese, Korean, and Japanese ethnicities. CA Cancer J Clin 2007; 57: 190-205.

6 Kamangar F, Dores GM, Anderson WF. Patterns of cancer incidence, mortality, and prevalence across five continents: defining priorities to reduce cancer disparities in different geographic regions of the world. J Clin Oncol 2006; 24: 2137-50.

7 Hayat MJ, Howlader N, Reichman ME, Edwards BK. Cancer statistics, trends, and multiple primary cancer analyses from the Surveillance, Epidemiology, and End Results (SEER) Program. Oncologist 2007; 12: 20-37.

8 Mettlin C, Jones G, Averette H, Gusberg SB, Murphy GP. Defining and updating the American Cancer Society guidelines for the cancer-related checkup: prostate and endometrial cancers. CA Cancer J Clin 1993; 43: 42-6.

9 Ye DW, Li CL. Epidemiological trends of prostate cancer: retrospect and prospect. China Oncol 2007; 17: 177-80.

$10 \mathrm{Gu}$ FL, Liu YL. Changing status of genitourinary cancer in recent 50 years. Chin J Urol 2002; 23: 88-90.

11 Zhang L, Ji GY, Li XM, Li SW, Gao HW, et al. The influence of mass screening for prostate cancer on the diagnostic status of the clinical prostate cancer. Chin J Urol 2004; 25: 103-4.
12 Li XM, Tsuji I, Kuwahara M, Zhang HF, Wang HL, et al. Mass screening of prostate cancer in Changchun City of China. Int Urol Nephrol 2004; 36: 541-8.

13 Kuwahara M, Tochigi T, Kawamura S, Ogata Y, Xu N, et al. Mass screening for prostate cancer: a comparative study in Natori, Japan and Changchun, China. Urology 2003; 61: 137-41.

14 Zhang HF, Wang HL, Xu N, Li SW, Ji GY, et al. Mass screening of 12027 elderly men for prostate carcinoma by measuring serum prostate specific antigen. Chin Med J (Engl) 2004; 117: 67-70.

15 Stamey TA, Yang N, Hay AR, McNeal JE, Freiha FS, et al. Prostate-specific antigen as a serum marker for adenocarcinoma of the prostate. N Engl J Med 1987; 317: 909-16.

16 Stamey TA, Kabalin JN, McNeal JE, Johnstone IM, Freiha F, et al. Prostate specific antigen in the diagnosis and treatment of adenocarcinoma of the prostate. II. Radical prostatectomy treated patients. J Urol 1989; 141: 1076-83.

17 Mettlin C, Murphy GP, Babaian RJ, Chesley A, Kane RA, et al. The results of a five-year early prostate cancer detection intervention. Investigators of the American Cancer Society National Prostate Cancer Detection Project. Cancer 1996; 77: 150-9.

18 Jemal A, Murray T, Ward E, Samuels A, Tiwari RC, et al. Cancer statistics 2005. CA Cancer J Clin 2005; 55: 10-30

19 Stamey TA, Caldwell M, McNeal JE, Nolley R, Hemenez M, et al. The prostate specific antigen era in the United States is over for prostate cancer: what happened in the last 20 years? J Urol 2004; 172: 1297-301

20 Ji GY, Zhang L, Zhao W, Gao HW, Kong XB, et al. Transrectal ultrasound-directed prostate biopsy can detect early prostate cancer. Chin J Androl 2005; 19: 22-4, 33 .

21 Gao HW, Li YL, Wu S, Wang YS, Zhang HF, et al. Mass screening of prostate cancer in a Chinese population: the relationship between pathological features of prostate cancer and serum prostate specific antigen. Asian J Androl 2005; 7: 159-63.

22 Li Y, Mao JH, Zhang L, Ji GY, Pan YZ, et al. Study on relationship between the expression of PSA mRNA and protein in the mononuclear cells of the peripheral blood and prostate cancer micrometastasis. Chin J Androl 2006; 20: 5-7.

23 Miyake H, Hara I, Kurahashi T, Inoue TA, Eto H, et al. Quantitative detection of micrometastases in pelvic lymph nodes in patients with clinically localized prostate cancer by real-time reverse transcriptasePCR. Clin Cancer Res 2007; 13: 1192-7.

24 Pan YZ, Xiao XY, Zhao D, Zhang L, Ji GY, et al. Application of surface-enhanced laser desorption/ionization time-of-flight-based serum proteomic array technique for the early diagnosis of prostate cancer. Asian J Androl 2006; 8: 45-51.

25 Li XM, Zhang L, Li J, Li Y, Wang HL, et al. Measurement of serum zinc improves prostate cancer detection efficiency in patients with PSA levels between $4 \mathrm{ng} / \mathrm{mL}$ and $10 \mathrm{ng} / \mathrm{mL}$. Asian J Androl 2005; 7: 323-8.

26 Zhang L, Ji GY, Zhang XY, Li XM, Wang WH, et al. Estimation of prostate cancer early diagnosis using free/total PSA ratio with a population-based screening data. J US-China Med Sci 2005; 1: 29-33.

27 Stephan C, Cammann H, Meyer HA, Lein M, Jung K. PSA and new biomarkers within multivariate models to improve early detection of prostate cancer. Cancer Lett 2007; 249: 18-29.

28 Pelzer AE, Volgger H, Bektic J, Berger AP, Rehder P, et al. The effect of percentage free prostate-specific antigen (PSA) level on the prostate cancer detection rate in a screening population with low PSA levels. BJU Int 2005; 96: 995-8.

29 Gregorio EP, Grando JP, Saqueti EE, Almeida SH, Moreira HA, et al. Comparison between PSA density, free PSA percentage and PSA density in the transition zone in the detection of prostate cancer in patients with serum PSA between 4 and $10 \mathrm{ng} / \mathrm{mL}$. Int Braz J Urol 2007; 33: 151-60.

30 Eggener SE, Yossepowitch O, Roehl KA, Loeb S, Yu X, et al. Relationship of prostate-specific antigen velocity to histologic findings in a prostate cancer screening program. Urology 2008; 71: 1016-9. 